\title{
Business cycle amplification with heterogeneous expectations
}

\author{
William A. Branch • Bruce McGough
}

Received: 10 May 2010 / Accepted: 13 May 2010 / Published online: 6 June 2010

(C) The Author(s) 2010. This article is published with open access at Springerlink.com

\begin{abstract}
This paper studies the implications for business cycle dynamics of heterogeneous expectations in a stochastic growth model. The assumption of homogeneous, rational expectations is replaced with a heterogeneous expectations model where a fraction of agents hold rational expectations and the remaining fraction adopt parsimonious forecasting models that are, in equilibrium, optimal within a restricted class. Our approach nests the literature on rational expectations in business cycle models with a recent approach based on adaptive learning. We demonstrate that (i.) heterogeneous expectations can lead to substantial improvement in the internal propagation of equilibrium business cycle models and (ii.) the internal propagation depends on the degree of heterogeneity. A calibrated model with heterogeneity provides a closer fit to business cycle data than its representative agent, rational expectations counterpart.
\end{abstract}

Keywords Heterogeneous expectations · Real business cycles · Restricted perceptions · Propagation

JEL Classification $\quad \mathrm{E} 52 \cdot \mathrm{E} 32 \cdot \mathrm{D} 83 \cdot \mathrm{D} 84$

We are grateful to George Evans, Mordecai Kurz, two anonymous referees, and participants at the SITE Workshop on Diverse Beliefs for comments.

W. A. Branch $(\varangle)$

Department of Economics, University of California, 3151 Social Science Plaza, Irvine, CA 92697-5100, USA

e-mail:wbranch@uci.edu

B. McGough

Department of Economics, Oregon State University, Corvallis, OR 97331, USA

e-mail: bruce.mcgough@oregonstate.edu 


\section{Introduction}

This paper studies business cycle dynamics in a framework that is similar to the stochastic neoclassical growth model, but which also incorporates heterogeneous expectations. We assume a competitive economy populated by two different types of households, each selecting plans for consumption/savings and labor supply. Agents in the first group are fully rational: they maximize lifetime utility taking as given prices and the behavior of the other group of households. These agents have rational expectations. Agents in the other group are boundedly rational: they hold restricted perceptions and employ a set of misspecified statistical models through which they form their expectations. With a statistical model in hand, the boundedly rational agents must decide on a household plan by satisfying a set of optimality conditions, which we discuss in detail below. A restricted perceptions equilibrium is a stochastic process whereby rational agents behave fully rationally and agents with restricted perceptions satisfy a least squares orthogonality condition that preserves many of the cross-equation restrictions that are a salient feature of rational expectations models (see Sargent (2008)). The results of this paper demonstrate that a heterogeneous expectations business cycle model is capable of increasing the internal propagation of real business cycle models.

Equilibrium business cycle models feature intertemporal decision making by households as the primary means of generating empirically plausible output dynamics. It is well known, however, that these models have weak internal propagation mechanisms: in response to technology shocks, households optimally adjust their holdings of capital and labor, but the aggregate time series properties closely resemble the process for technology; that is, there is little additional impulse implied by the intertemporal decisions of households. For example, Cogley and Nason (1995) illustrate that in response to transitory technology shocks, the time series data for output exhibit a hump-shaped response, with output continuing to increase following the shock. Standard RBC models do not exhibit similar impulse responses.

As an alternative, Kurz et al. $(2003,2005)$ introduce belief heterogeneity as a mechanism for propagating business cycle fluctuations. ${ }^{1}$ These pioneering papers demonstrate that the diversity of beliefs - a defining feature of a rational belief equilibrium - provide empirically realistic business cycle dynamics even with shocks that are significantly smaller than those in the standard RBC framework. In a rational belief equilibrium, heterogeneous expectations are the driving force of business cycle dynamics, and because of them there is a reason and channel for monetary policy to stabilize the real side of the economy (Motolese 2001, 2003).

This paper is motivated in part by the work of Kurz et al. $(2003,2005)$ and begins with the observation that the implicit sophistication required by agents to form rational expectations may be too great for many economic agents: rational expectations require that forecasters have the ability to compute expectations conditional on the true distribution of the endogenous variables. As an alternative, we assume that a fraction of the population has limited sophistication, or restricted perceptions, in forecasting.

\footnotetext{
1 Belief diversity can help explain many features of the economy. See Sect. 5 for an extensive discussion of the related literature on diverse beliefs.
} 
We do not abandon the hallmark cross equation restrictions of rational expectations models, however, and impose that all agents' forecasts are optimal within their (possibly) restricted class. There is a growing literature that models agents as boundedly rational, and one goal of this paper is to show that the insights from Kurz et al. (2003, 2005) carry over to an economy with a mix of boundedly rational and fully rational agents.

In real business cycle models, current period decisions for consumption, savings, and labor supply depend on expectations of the future. The standard approach to modeling household behavior is to assume that preferences, constraints, and technologies are the primitives of the model and to assume expectations consistent with the dynamic programming problem. Models of bounded rationality relax one or more of these primitive assumptions. For example, in Krusell and Smith (1996) households have rational expectations but they make consumption and savings decisions according to (optimal) linear decision rules. In other models of bounded rationality, the beliefs of the agents are primitive, and the behavioral rules are imposed to be consistent with those beliefs. For example, in Evans and Honkapohja (2006) agents are able to form one step-ahead forecasts and make consumption and savings decisions that satisfy their one period Euler equation. In Preston (2006), agents form forecasts at all horizons and make decisions to satisfy their Euler equations at all forward iterations, as well as their lifetime budget constraint.

A cognitive dissonance arises when agents have limited sophistication in forecasting but are able to solve for their infinite horizon optimal plan given those beliefs. Therefore, our approach to modeling boundedly rational decision making follows, and generalizes, the Euler equation technique of Sargent (1993) and Evans and Honkapohja (2001). Following these earlier researchers, we take the forecasting model as primitive, but we also allow for the possibility that agents may have $N$-period planning horizons with $N \geq 1$. We then require that agents make consumption/savings/labor/leisure decisions consistent with their Euler equation iterated forward $N$ periods. Allowing for an $N$-period planning horizon increases the flexibility of the Euler equation approach while maintaining its intuitive appeal.

With a fraction of agents fully rational, and the remaining agents boundedly optimal, we show that heterogeneity can enhance the internal propagation of equilibrium business cycle models. The key insight is that boundedly rational agents react more strongly to innovations in real wages and interest rates that result from technology shocks. Because they have limited sophistication, their misspecified statistical models are not able to completely forecast how temporary shocks impact future endogenous variables. As a result, boundedly rational agents will fail to smooth consumption as much as a fully rational agent at the time the shock is realized. The internal propagation of the business cycle model is altered precisely because of the distinct individual behavior of boundedly rational agents.

We demonstrate that a calibrated version of the business cycle model with heterogeneous expectations is able to fit US quarterly data significantly better than the model under rational expectations, i.e., the real business cycle model. That heterogeneity in expectations, via the results here and in Kurz et al. (2005), can explain business cycle facts provide a compelling argument in favor of diverse beliefs over rational expectations. Furthermore, the presence of diverse beliefs may have important 
policy implications: as mentioned, Kurz et al. show that diverse beliefs lead to the need for, and effectiveness of monetary policy; separately, Branch and McGough (2009) demonstrate, in a New Keynesian model with a fraction of households and firms rational and a fraction adaptive, that standard monetary policy advice can be overturned. In particular, policy that satisfies a "Taylor principle" by adjusting nominal interest rates more than one for one with inflation can lead to instability in case of expectations heterogeneity while it would lead to stability in a representative agent model. Similarly, De Grauwe (2010) assumes that there are two types of agents, optimists and pessimists regarding the output gap, with the fraction being determined endogenously each period according to their forecasting success. DeGrauwe finds that inflation targeting can lead to waves of optimism and pessimism that destabilize both inflation and the output gap.

This paper proceeds as follows. Section 2 presents an equilibrium model with heterogeneous expectations. Section 3 presents the main insights into business cycle propagation in a simple neoclassical model. Section 4 presents quantitative results in a calibrated real business cycle model. Section 5 connects our work to the literature, and Sect. 6 concludes.

\section{The model}

We modify the benchmark real business cycle (RBC) model to incorporate heterogeneous expectations. We follow Kurz et al. (2005) and include variable capacity utilization as a proxy for resource unemployment. The availability of underemployed resources that can be better utilized in response to certain boundedly rational beliefs plays an important role in the ability of the heterogeneous expectations model to fit empirical regularities, much as it did in Kurz et al. (2005). To facilitate exposition, we begin with a brief review of the RBC model (for a detailed discussion, see King and Rebelo (1999)).

\subsection{The RBC model}

There is a continuum of identical households and a continuum of identical firms. Firms rent capital, hire labor, select their utilization rate for capital, and produce consumption goods; households consume goods, and supply labor and capital. There are three competitive markets—consumption goods, capital, and labor-and prices are written with consumption as the numeraire.

The representative household's problem is given by

$$
\begin{aligned}
\max _{\left\{C_{t}, S_{t}, L_{t}, H_{t}\right\}} & E_{0} \sum_{t \geq 0} \beta^{t} u\left(C_{t}, L_{t}\right) \\
\text { s.t. } & C_{t}+S_{t}=\left(1+R_{t}\right) S_{t-1}+W_{t} H_{t}
\end{aligned}
$$

where $C_{t}$ is consumption, $S_{t}$ is savings, $R_{t}$ is the real net return on savings, $W_{t}$ is the real wage, $H_{t}$ is the quantity of labor supplied, and $L_{t}$ is leisure: agents have a 
unit endowment of time each period; thus $L_{t}+H_{t}=1$. The associated first-order conditions are given by

$$
\begin{aligned}
u_{c}\left(C_{t}, L_{t}\right) & =\beta E_{t} u_{c}\left(C_{t+1}, L_{t+1}\right)\left(1+R_{t+1}\right) \\
u_{c}\left(C_{t}, L_{t}\right) W_{t} & =u_{l}\left(C_{t}, L_{t}\right) .
\end{aligned}
$$

Equation (3) is often called the Euler equation and captures the inter-temporal consumption/savings decision faced by the household; Eq. (4) captures the contemporaneous, or intra-temporal, consumption/leisure trade-off.

Firms have access to a constant returns to scale technology

$$
Y_{t}=Z_{t} f\left(U_{t} K_{t}, H_{t}\right),
$$

where $K$ is aggregate capital stock, $H$ are hours of labor, and $U$ is the capacity utilization rate. The variable $Z_{t}$ is a serially correlated productivity shock satisfying $Z_{t}=V_{t} Z_{t-1}^{\rho}$, where $|\rho|<1$ and $V_{t}$ is i.i.d. with small, compact, positive support. In maximizing profits, firms hire labor and capital from competitive factor markets, decide on their utilization rate $U$ and face no inter-temporal trade-offs. They select their variable capacity utilization rate by satisfying the following condition:

$$
\alpha Z_{t} U_{t}^{\alpha-1} K_{t}^{\alpha-1} N_{t}^{1-\alpha}=\delta^{\prime}\left(U_{t}\right)
$$

where $\delta\left(U_{t}\right)$ is the depreciation rate with $\delta^{\prime}, \delta^{\prime \prime}>0$. This condition balances the marginal product of capacity utilization against its marginal cost, the marginal increase in the rate of depreciation. (King and Rebelo 1999; Jaimovich and Rebelo 2009) introduce capacity utilization as a mechanism for enhancing the propagation of productivity shocks. In addition to the direct effect of technology shocks, $Z_{t}$, there is an indirect effect acting through $U_{t}$. Positive shocks to technology directly increase the marginal product of capital, but also increase amplification by raising the marginal product of capital utilization; hence $U_{t}$. Thus, technology shocks increase the productivity of capital and the intensity at which capital is employed. These assumptions imply that relative prices satisfy

$$
\begin{aligned}
W_{t} & =Z_{t} f_{h}\left(U_{t} K_{t}, H_{t}\right) \\
R_{t} & =Z_{t} f_{k}\left(U_{t} K_{t}, H_{t}\right)-\delta\left(U_{t}\right) .
\end{aligned}
$$

The model is closed by the market clearing condition $S_{t}=K_{t+1}$, which, together with the pricing relations (6) and (7), yields the capital accumulation equation

$$
K_{t+1}=Z_{t} f\left(U_{t} K_{t}, H_{t}\right)+\left(1-\delta\left(U_{t}\right)\right) K_{t}-C_{t} .
$$

Definition An equilibrium of the real business cycle model is a collection of processes $\left\{C_{t}, K_{t}, H_{t}, L_{t}, R_{t}, W_{t}, S_{t}, U_{t}\right\}$ satisfying (2)-(8), the representative household's transversality condition, $S_{t}=K_{t+1}$ and $L_{t}+H_{t}=1$. 
For the remainder of the paper, we adopt the functional forms in King and Rebelo (1999):

$$
f(K, H)=K^{\alpha} H^{1-\alpha} \text { and } u(C, L)=\log C+\Theta \frac{L^{1+\eta}}{1+\eta} .
$$

With this specification (and more generally) it can be shown that the RBC model has a unique rational expectations equilibrium. Analysis of this equilibrium is often accomplished by log-linearizing the system (2)-(8) about the unique deterministic steady state. The resulting reduced form system of linear expectational difference equations may then be solved using, for example, the techniques of Blanchard and Kahn (1980); the solution to the linearized system is a covariance-stationary vector autoregression that may be used to compute impulse response functions and aggregate co-movements.

\subsection{The heterogeneous business cycle model}

We modify the benchmark RBC model by assuming heterogeneous households. Households differ in the way they form expectations and in the way they behave given their forecasts: we take the forecasting model as the primitive and assume decision-making behavior consistent with the boundedly rational forecasting model. We first describe the behavior of the boundedly rational agents before defining the restricted perceptions equilibrium for the heterogeneous expectations business cycle (HBC) model.

\subsubsection{Bounded rationality}

In most dynamic stochastic general equilibrium models, rational agents are assumed to make decisions by forming contingency plans that solve their stochastic dynamic programming problem. Forming contingency plans requires significant sophistication on the part of agents, both as forecasters and as decision makers. To model the behavior of agents with limited sophistication, we adopt the approach commonly used in the econometric learning literature: agents form expectations at finite horizons using forecasting models; then agents make current decisions based on these expectations.

Our approach differs from that taken by Kurz et al. (2003, 2005). In Kurz et al. households form heterogeneous beliefs about future monetary and technology shocks. A key insight from the rational belief model is that diverse beliefs expand the state space as agents form beliefs about future beliefs. Then given these beliefs, the agents solve their dynamic programming problem. We introduce boundedly rational agents of the type studied by Evans and Honkapohja (2001), and others, in the econometric learning literature. ${ }^{2}$ This literature replaces rational expectations with expectations generated from an econometric forecasting model, thereby implicitly modeling agents like econometricians. Empirical results in Milani (2007) and Mavroeidis et al. (2009) provide evidence in favor of bounded rationality of this form over rational expectations.

\footnotetext{
2 The econometric learning literature encompasses a wide range of alternatives to rational expectations. Among them, there is the least-squares updating of Marcet and Sargent (1989a), the optimal misspecification of Sargent (1999), and the endogenous switching between predictors of Brock and Hommes (1997).
} 
Our viewpoint is informed as well by Branch (2004) who provides evidence from the Michigan Survey of Consumers that households are split between rational and adaptive agents.

As mentioned in the Sect. 1, there have been two main approaches to modeling household behavior when agents are boundedly rational (and estimating their forecasting models). The Euler equation technique, or "Euler equation learning," assumes households forecast one period ahead and make current decisions to satisfy their one period Euler equation. As an alternative, Preston (2006) has agents make forecasts at all horizons, and make decisions by simultaneously satisfying the lifetime budget constraint and the Euler equations at all forward iterates. In this paper, we generalize the Euler equation technique by taking the beliefs, in the form of both a forecasting model and a forecasting horizon, as the primitive; and we specify boundedly rational decision rules that are consistent with the agents' Euler equation iterated according to the forecasting horizon.

We begin by describing agents' behavioral decision rules which are consistent with a given forecasting horizon; then, in the next subsection, we describe the specifics of the forecasting models.

\section{Bounded rationality: behavioral rules}

Given its forecasting model and planning horizon, we base the households' behavioral primitives on the usual household problem, as given by (1). Instead of assuming our agents solve the dynamic programming problem, we follow Evans and Honkapohja (2006) and specify agent behavior by taking the log-linearized versions of some of the associated optimality restrictions as primitive. First, though, some notational issues. Denote by lowercase letters without subscripts the steady-state values of variables, and define lowercase letters with subscripts as being written in proportional deviation from steady state. Finally, a superscript will indicate a type-specific variable, whereas no super-script indicates an aggregate quantity. For example, $k$ is the steady-state value of aggregate capital, $k_{t}$ is the proportional deviation of time $t$ aggregate capital from the steady-state value, and $c_{t}^{\tau}$ is the proportional deviation of the time $t$ consumption of an agent of type $\tau$ from its steady-state value. ${ }^{3}$

The log-linearized versions of Eqs. (2), (3), and (4) are given by

$$
\begin{aligned}
s_{t}^{\tau}+\frac{c}{k} c_{t}^{\tau}-w \frac{h}{k} h_{t}^{\tau} & =\beta^{-1} s_{t-1}^{\tau}+w \frac{h}{k} w_{t}+r r_{t} \\
c_{t}^{\tau} & =E_{t}^{\tau} c_{t+N^{\tau}}^{\tau}-\beta r \sum_{i=1}^{N^{\tau}} E_{t}^{\tau} r_{t+i} \\
c_{t}^{\tau}+\eta \frac{h}{l} h_{t}^{\tau} & =w_{t} .
\end{aligned}
$$

\footnotetext{
3 Boundedly rational forecasts will be defined in such a way as to guarantee that all type-specific variables have the same steady-state values, that is, the steady-state value of consumption etc. for agents of type $\tau_{1}$ and $\tau_{2}$ will be the same.
} 
Here, $E_{t}^{\tau}$ is agent $\tau$ 's expectations operator, which we specify in the next section. Equation (11) is obtained by iterating the log-linearized Euler equation forward $N^{\tau}$ steps. Under rational expectations, or infinite horizon learning, (11) will be satisfied for all $N^{\tau}$. Instead, we identify a household type $\tau$ as one having a forecasting/planning horizon of $N^{\tau}$ periods. Then, our behavioral model assumes that a boundedly rational plan satisfies the household's flow budget constraint (10), their $N^{\tau}$ period Euler equation (11), and their intra-temporal condition (12). Intuitively, the condition (11) is a simple rule for consumption requiring that a boundedly optimal agent with a $N^{\tau}$ period horizon select a consumption level in time $t$ so as to equate the marginal utility at $t$ with the expected discounted marginal utility at $t+N^{\tau}$.

Solving these equations for agent $\tau$ 's contemporaneous choices, we get

$$
\begin{aligned}
& c_{t}^{\tau}=E_{t}^{\tau} c_{t+N^{\tau}}^{\tau}-\beta r \sum_{i=1}^{N^{\tau}} E_{t}^{\tau} r_{t+i} \\
& h_{t}^{\tau}=\frac{l}{\eta h} w_{t}-\frac{l}{\eta h} E_{t}^{\tau} c_{t+N^{\tau}}^{\tau}+\frac{\beta l r}{\eta h} \sum_{i=1}^{N^{\tau}} E_{t}^{\tau} r_{t+i} \\
& s_{t}^{\tau}=\beta^{-1} s_{t-1}^{\tau}+r r_{t}+\frac{\eta b+l}{\eta k} w_{t}-\chi E_{t}^{\tau} c_{t+N^{\tau}}^{\tau}+\beta r \chi \sum_{i=1}^{N^{\tau}} E_{t}^{\tau} r_{t+i},
\end{aligned}
$$

where $\chi=\frac{w l+c \eta}{\eta k}$. Equations (13)-(15) identify how agent $\tau$ makes decisions. Importantly, these equations show how agent $\tau$ 's time $t$ decisions are determined by his savings, $s_{t-1}^{\tau}$, time $t$ prices, and his time $t$ forecasts of the future.

The form of Eq. (13) warrants further comment. By incorporating the $N$-step Euler equation into agent $\tau$ 's behavioral primitives, household decisions are based not only on forecasts of tomorrow, but also of events further in the future. We view the $N$-step Euler equation as a natural behavioral primitive: agent $\tau$ forecasts future consumption and trade-offs and chooses consumption today so that marginal benefit equals expected marginal cost. While this behavior is natural, it does not characterize fully optimal behavior, even given agent $\tau$ 's subjective beliefs (as captured by the expectations operator $E^{\tau}$ ): the agent's planning horizon is finite and does not account for the transversality condition ex-ante. We say that an agent making decisions based on (13)-(15) is boundedly rational, with an $N^{\tau}$-period planning horizon. ${ }^{4}$ A detailed discussion is provided in Sect. 2.2.2.

\footnotetext{
4 To study whether an equilibrium is stable under learning in a New Keynesian model, Evans and Honkapohja (2006) employed similar behavioral assumptions, but used one period planning horizons and correctly specified forecasting models. They called their implementation "Euler equation learning." Evans and McGough (2009) instead assume that agents make decisions based on forecasts of shadow prices. They show that under shadow price learning, agents with correctly specified forecasting models may learn to make optimal decisions. Finally, Preston (2006) takes as behavioral primitives both the Euler equations at all iterations, and the lifetime budget constraint: he calls this implementation "infinite horizon learning," and he finds that it may result in stability conditions which differ from those predicted by Euler equation learning.
} 


\section{Bounded rationality: forecasting functions}

The beliefs of a given agent are fully specified by the functional form of the forecasting model together with a vector of perceived parameters and a forecasting horizon. Rational expectations require a very high degree of sophistication by forecasters. They must be able to compute forecasts at all future horizons, and these forecasts must coincide with conditional expectations taken with respect to the true distribution of the endogenous state variables, which themselves are functions of these forecasts. Instead, we follow Branch and Evans (2006) and assume that those agents who do not have the sophistication to form rational expectations, adopt parsimonious forecasting models. In particular, we assume their forecasting models are univariate, and thereby underparameterized.

In a rational expectations equilibrium, capital depends linearly on lagged capital and the productivity shock. Motivated by this observation and our assumption that agents adopt parsimonious forecasting models, we assume that boundedly rational agents of type $\tau$ form their forecasts from the following perceived laws of motion:

$$
\begin{aligned}
c_{t}^{\tau} & =\psi_{c}^{\tau} s_{t-1}^{\tau}+\varepsilon_{c, t} \\
s_{t}^{\tau} & =\psi_{s}^{\tau} s_{t-1}^{\tau}+\varepsilon_{s, t} \\
r_{t} & =\psi_{r}^{\tau} r_{t-1}+\varepsilon_{r, t},
\end{aligned}
$$

where $\varepsilon_{j, t}$ is a perceived white noise error. Expectations are formed by iterating the perceived laws of motion forward $N^{\tau}$ periods. These forecasting models capture several desirable features of reasonable forecasting behavior by agents with limited sophistication. First, as univariate models, they are parsimonious. In a representative agent model, a rational agent would forecast future consumption as depending on both future savings levels and future prices. These models are in the spirit of such a forecasting model but subject to the parsimony restriction. Second, these forecasting models impose the plausible assumption that aggregate prices are observable but capital holdings of other types of agents are not observable. Third, these perceived laws of motion resemble linear regression models and so the implicit assumption is that even though these agents have limited sophistication, they still forecast like good econometricians. The next subsection details how the regression parameters, $\psi_{c}, \psi_{s}, \psi_{r}$ are pinned down within a restricted perceptions equilibrium.

Parsimony in forecasting is often favored because of model uncertainty, computational constraints, degree of freedom limitations, etc. In this simple model, it may seem forced that agents would favor parsimony; after all the correct forecasting model only involves one additional variable which agents are already forecasting anyway. However, this assumption is a reasonable approximation to real economies where adopting a correctly specified model requires too much sophistication, computing power, degrees of freedom, etc., and so some agents make decisions based on forecasting models that are underspecified. The purpose of this paper is to show that a model with heterogeneity in expectations, and as a result heterogeneity in decision making, has important implications for business cycle dynamics.

The timing of observables requires brief comment. It is natural to assume that time $t$ prices are observed by agents when forecasts are made; therefore, we assume 
that $E_{t}^{\tau} r_{t}=r_{t}$. It is less obvious whether time $t$ values of choice variables are observed by agents when forecasts are made. The literature on bounded rationality, e.g., Evans and Honkapohja (2001), views both options as reasonable. Throughout, we maintain the contemporaneous-timing convention: $E_{t}^{\tau} s_{t}^{\tau}=s_{t}^{\tau}$, so that $E_{t}^{\tau} c_{t+N^{\tau}}^{\tau}=$ $\psi_{c}^{\tau}\left(\psi_{s}^{\tau}\right)^{N^{\tau}-1} s_{t}^{\tau}$. Some may object to the contemporaneous timing convention since it imposes that choices and (boundedly rational) forecasts are made simultaneously. All of the results presented in this paper, however, are robust to the lagged timing convention, $E_{t}^{\tau} c_{t+N^{\tau}}^{\tau}=\psi_{c}^{\tau}\left(\psi_{s}^{\tau}\right)^{N^{\tau}} s_{t-1}^{\tau}$.

Given the maintained assumptions on the information sets of boundedly rational agents, it follows that

$$
\sum_{i=1}^{N^{\tau}} E_{t}^{\tau} r_{t+i}=\frac{\psi_{r}^{\tau}}{1-\psi_{r}^{\tau}}\left(1-\left(\psi_{r}^{\tau}\right)^{N^{\tau}}\right) r_{t}
$$

Note that agent $\tau$ 's forecasts — and hence beliefs — are completely characterized by the perceived parameters $\psi^{\tau}=\left(\psi_{c}^{\tau}, \psi_{s}^{\tau}, \psi_{r}^{\tau}\right)$. These forecasts may be combined with the behavioral equations (13)-(15) to write the contemporaneous decisions of agent $\tau$ as functions of prices and his lagged savings.

\subsubsection{Discussion on bounded rationality}

The heterogeneous expectations business cycle framework emphasizes the interaction between rational and boundedly rational households. Our approach to modeling bounded rationality is to assume certain behavioral rules for deciding on consumption/savings plans and to impose a parsimony in forecasting rules. A few of the details to this approach require further comment.

1. The Euler equation approach. Following Sargent (1993) and Evans and Honkapohja (2001), we argue that the Euler equation approach to consumption decisions is reasonable. Given that boundedly rational households do not solve a dynamic programming problem, any specification of the consumption decision is, to some extent, an ad-hoc rule-of-thumb; however, we find the assumptions imposed by the Euler equation technique at any given forecasting horizon, particularly appealing: imposing that agents satisfy the Euler equation is the simplest, economically intuitive consumption rule that can be formulated for households. It simply requires that they equate their (expected) marginal rate of substitution with the marginal rate of transformation. Marginal and forward-looking decision making are, in our view, hallmarks of modern macroeconomics. Modeling boundedly rational behavior this way is the standard approach since Marcet and Sargent (1989b) and Sargent (1993)..$^{5}$

The Euler equation approach has been criticized for requiring agents to forecast their own future consumption; however, we feel that such forecasts are very

\footnotetext{
${ }^{5}$ It is possible to impose that consumption is determined by an alternative rule, for example, a linear consumption rule as in Krusell and Smith (1996), though such analysis is beyond the scope of the present paper.
} 
natural for a reasonably well-behaved household. Indeed, one of the conditions for household optimization is a balancing, on the margin, between current and future consumption. In a rational expectations equilibrium, consumption is related to the state variables, $s_{t-1}, r_{t}$. The optimizing household needs to plan the level of future consumption and so it is natural to assume that they infer the relationship between future consumption and the current state variables. Extending this reasoning to boundedly rational agents, they engage in this marginal decision making by inferring, via their econometric forecasting models, the relationship between consumption, savings, and interest rates with the observable values of the state variables.

2. Underparameterized forecasting models. Our approach introduces a preference for forecasting parsimony as an underlying cause of bounded rationality. These agents find formulating, estimating, and constructing forecasts based on correctly specified models too costly. Moreover, if agents are worried that their model is misspecified, then specifying a parsimonious model is often recommended. There is empirical evidence by Branch (2004) that some households in the Michigan survey employ simple univariate forecasting models.

A possible concern is that the form of the forecasting model is inconsistent with the actual decision rule of the agent that depends on both capital and interest rates. This is a natural consequence of the consumption rule imposed onto households and the restricted perceptions assumption. It might be expected that a household will detect this inconsistency and respecify their forecasting model. However, Sect.2.3, below, applies the concept of a restricted perceptions equilibrium to the business cycle model. Within a restricted perceptions equilibrium, households are unable to detect the misspecification in their econometric model. That actual decisions depend on interest rates will imply that households will account for this correlation via the omitted variable bias in their least squares coefficient estimates. Although we impose this model misspecification, the equilibrium preserves the cross-equation restrictions that are hallmarks of the rational expectations approach.

3. Finite forecasting horizon. An alternative to assuming an $N$-step forecasting/ planning horizon is to adopt the infinite horizon approach as emphasized by Preston. ${ }^{6}$ While this alternative is natural, we adopt the finite horizon Euler equation approach because it avoids the cognitive dissonance that boundedly rational agents are limited in their forecasting ability - to the extent that they have underspecified forecasting models_-but are unconstrained in their ability to solve an infinite horizon planning problem. ${ }^{7}$

We close this discussion by noting that the forecasting horizon, and the fraction of rational versus boundedly rational agents, are key free parameters that affect the business cycle mechanics of the model. The remainder of the paper proceeds by first illustrating how these parameters — which, in combination with the decision rules, fully

\footnotetext{
6 Another alternative to our $N$-step Euler equation approach is to impose that agents repeated solve an $N$-period problem and thereby obtain a consumption rule. The $N$-step approach has the advantage of delivering a time invariant decision rule. It would be interesting for future research to study an alternative model where there is a fraction of agents who (repeatedly) solve for a finite period consumption plan.

7 Also, it is an empirical observation that professional forecasters only forecast so far into the future.
} 
define the behavior of the boundedly rational households-affect the propagation features of the equilibrium business cycle model. Then, the paper focuses on a calibrated version of the model capable of replicating observed quantitative features of the US economy. In this exercise, the forecasting horizon and the fraction of rational agents are calibrated to minimize the distance between the model implied autocorrelation function and the autocorrelation function for US output data.

\subsection{Equilibrium}

We now describe equilibria in the heterogeneous expectations business cycle (HBC) model. There are $M+1$ agent types: there is a proportion $\theta$ of rational agents, and a proportion $(1-\theta) \phi^{\tau}$ of boundedly rational agents of type $\tau$, where $\sum_{\tau=1}^{M} \phi_{\tau}=1$. For notational simplicity, time-subscripted variables associated to rational agents have no superscript.

Definition Given beliefs and forecasting horizons $\left\{\psi^{\tau}, N^{\tau}\right\}_{\tau=1}^{M}$, proportions $\theta$ and $\left\{\phi^{\tau}\right\}_{\tau=1}^{M}$, an equilibrium of the heterogeneous expectations business cycle model is a collection

$$
\left\{\left\{s_{t}^{\tau}, c_{t}^{\tau}, h_{t}^{\tau}\right\}_{\tau=1}^{M}, s_{t}, c_{t}, h_{t}, k_{t}, r_{t}, w_{t}\right\}
$$

satisfying

$$
\begin{aligned}
c_{t} & =E_{t} c_{t+1}-\beta r E_{t} r_{t+1} \\
s_{t} & =\beta^{-1} s_{t-1}+w \frac{h}{k} w_{t}+r r_{t}-\frac{c}{k} c_{t}+w \frac{h}{k} h_{t} \\
c_{t}^{\tau}+\eta \frac{h}{l} h_{t}^{\tau}= & w_{t}, \quad \tau=1, \ldots, M+1 \\
\left(\begin{array}{c}
c_{t}^{\tau} \\
h_{t}^{\tau} \\
s_{t}^{\tau}
\end{array}\right)= & A^{\tau}\left(N^{\tau}, \psi^{\tau}\right)\left(\begin{array}{c}
s_{t-1}^{\tau} \\
w_{t} \\
r_{t}
\end{array}\right), \quad \text { for } \tau=1, \ldots, M \\
k_{t}= & \theta s_{t-1}+(1-\theta) \sum_{\tau=1}^{M} \phi^{\tau} s_{t-1}^{\tau} \\
r_{t}= & (1-\alpha)\left(\frac{r+\delta}{r}\right)\left(h_{t}-k_{t}\right)+\frac{r+\delta}{r} z_{t} \\
& +\left(\frac{(\alpha-1)(r+\delta)}{r(\xi+1-\alpha)}\right)\left((1-\alpha)\left(h_{t}-k_{t}\right)+z_{t}\right) \\
w_{t}= & \alpha\left(k_{t}-h_{t}\right)+z_{t}+\frac{\alpha}{\xi+1-\alpha}\left((1-\alpha)\left(h_{t}-k_{t}\right)+z_{t}\right) \\
z_{t}= & \rho z_{t-1}+v_{t} .
\end{aligned}
$$


Capacity utilization has been solved out. Here, $\xi=\frac{\delta^{\prime \prime}(u)}{u \delta^{\prime}(u)}$ is the steady-state elasticity of depreciation with respect to capacity utilization, and (23) is obtained by imposing agents' boundedly rational forecasts into (13)-(15).

To guarantee that rational agents are satisfying their transversality condition, and to remain true to the linearization of the model, we focus on bounded solutions to the above system, which may be computed in the usual way. The definition of an equilibrium to the $\mathrm{HBC}$ model illustrates that a heterogeneous expectations equilibrium can be found by solving the associated rational model (20)-(27). In Branch and McGough (2004) it was shown that the number and nature of heterogeneous expectations equilibria may be very different from a model with homogeneous, rational expectations. In the following, we restrict attention to HBC models with unique bounded solutions.

Although boundedly rational agents hold misspecified forecasting models, we require that they forecast in a statistically optimal manner, i.e., we require that the forecast model parameters are optimal linear projections. It follows that the $\psi^{\tau}$ satisfy the following least squares orthogonality conditions

$$
\begin{aligned}
& E s_{t-1}^{\tau}\left(c_{t}^{\tau}-\psi_{c}^{\tau} s_{t-1}^{\tau}\right)=0 \\
& E s_{t-1}^{\tau}\left(s_{t}^{\tau}-\psi_{s}^{\tau} s_{t-1}^{\tau}\right)=0 \\
& E r_{t-1}\left(r_{t}-\psi_{r}^{\tau} r_{t-1}\right)=0 .
\end{aligned}
$$

For each orthogonality condition, the expectation is taken with respect to the unconditional equilibrium distribution. Notice that in case these orthogonality conditions are satisfied, all boundedly rational agents have the same beliefs, which we now simply label as $\psi$, though these agents may still differ with respect to planning horizon. Least squares orthogonality conditions appear frequently in the macroeconomics literature. Sargent (2008); Evans and Honkapohja (2001) show that learning models often converge to parameters that satisfy orthogonality conditions like (28)-(30). A key feature of beliefs that satisfy orthogonality conditions like (28)-(30) are that within the context of their forecasting model, agents are unable to detect their misspecification. We are now ready to define our main equilibrium concept.

Definition Given the forecasting horizons $\left\{N^{\tau}\right\}_{\tau=1}^{M}$, and proportions $\theta$, and $\left\{\phi^{\tau}\right\}_{\tau=1}^{M}$, a restricted perceptions equilibrium is a collection

$$
\left\{\left\{s_{t}^{\tau}, c_{t}^{\tau}, h_{t}^{\tau}\right\}_{\tau=1}^{M}, s_{t}, c_{t}, h_{t}, k_{t}, r_{t}, w_{t}\right\}
$$

such that

1. given $\psi,\left\{\left\{s_{t}^{\tau}, c_{t}^{\tau}, h_{t}^{\tau}\right\}_{\tau=1}^{M}, s_{t}, c_{t}, h_{t}, k_{t}, r_{t}, w_{t}\right\}$ is an equilibrium of the HBC model;

2. $\psi$ satisfies the least squares orthogonality conditions (28)-(30).

We may compute the restricted perceptions equilibria (RPE) as follows. Fix the primitives $\theta,\left\{N^{\tau}, \phi^{\tau}\right\}_{\tau=1}^{M}$. Write beliefs as follows: $\psi^{\tau}=\left(\psi_{c}^{\tau}, \psi_{s}^{\tau}, \psi_{r}^{\tau}\right)^{\prime}$ and $\psi=$ $\left(\left(\psi^{1}\right)^{\prime}, \ldots,\left(\psi^{M}\right)^{\prime}\right)^{\prime}$. Also, let $x_{t}^{\tau}=\left(c_{t}^{\tau}, s_{t}^{\tau}, r_{t}\right)^{\prime}$. Given beliefs, $\psi$, the equilibrium of the HBC model may be determined by solving the associated rational model 
(20)-(27), using, for example, the Blanchard-Khan technique. This solution provides the invariant distribution used to compute the expectations in the orthogonality conditions (28)-(30). We define the map $T^{\tau}\left(\cdot ; \theta,\left\{N^{\tau}, \phi^{\tau}\right\}_{\tau=1}^{M}\right): \mathbb{R}^{3 M} \rightarrow \mathbb{R}^{3}$ as follows:

$$
E\left(x_{t}^{\tau}-T^{\tau}\left(\psi ; \theta,\left\{N^{\tau}, \phi^{\tau}\right\}_{\tau=1}^{M}\right) s_{t-1}^{\tau}\right) s_{t-1}^{\tau}=0_{3 \times 1}
$$

and we define $T\left(\cdot ; \theta,\left\{N^{\tau}, \phi^{\tau}\right\}_{\tau=1}^{M}\right): \mathbb{R}^{3 M} \rightarrow \mathbb{R}^{3 M}$ by

$T\left(\psi ; \theta,\left\{N^{\tau}, \phi^{\tau}\right\}_{\tau=1}^{M}\right)=\left(T^{1}\left(\psi ; \theta,\left\{N^{\tau}, \phi^{\tau}\right\}_{\tau=1}^{M}\right)^{\prime}, \ldots, T^{M}\left(\psi ; \theta,\left\{N^{\tau}, \phi^{\tau}\right\}_{\tau=1}^{M}\right)^{\prime}\right)^{\prime}$.

The RPE is (numerically) computed as the fixed point $\psi=T\left(\psi ; \theta,\left\{N^{\tau}, \phi^{\tau}\right\}_{\tau=1}^{M}\right)$.

\section{Inelastic labor supply: comparative dynamics}

We begin the analysis with an illustrative example. The HBC framework is flexible enough to incorporate many forms of heterogeneity. This section provides critical insights into the way in which heterogeneity alters business cycle dynamics by restricting attention to the special case of inelastic labor supply, i.e., the Ramsey model and constant capacity utilization. The next section presents quantitative results for the HBC with elastic labor supply and variable capacity utilization.

Because the complicated nature of the model makes analytic results intractable, this section presents numerical analysis. We simplify the model by focusing on two agent types: a proportion $\theta$ who are rational, and a proportional $1-\theta$ who are boundedly rational with an $N$-period planning horizon. The functional forms for utility and production are given by (9). For results presented here, we employ the following parameter values (consistent with annual data): $\beta=.95, \alpha=1 / 3, \delta=.1$ and $\rho=.9$. In this section, we let $\xi \rightarrow \infty, \Theta=0$ and focus on the model with inelastic labor supply; this allows us to explore more intuitively the individual and aggregate implications of bounded rationality.

\subsection{Boundedly rational agent behavior}

We begin by comparing the individual behavior of rational agents to boundedly rational agents. This subsection assumes the economy is in a representative agent environment, with $\theta=1$, and a zero mass of boundedly rational agents. In this subsection, there is no heterogeneity and so, for the moment, beliefs are fixed. We now illustrate how forecasting/planning horizons alter individual behavior.

Figure 1 plots the boundedly rational agent type's consumption and savings responses to a technology shock. To construct this figure, we performed the following experiment: we begin by computing the impulse response functions from the model following a $1 \%$ shock to productivity when $\theta=1$, i.e., the fully rational case. The impulse responses provide the consumption and savings behavior of the rational agents as well as a simulated series of prices. Given these data, we compute, via the behavioral equations, the corresponding impulse responses for the zero-mass boundedly rational 

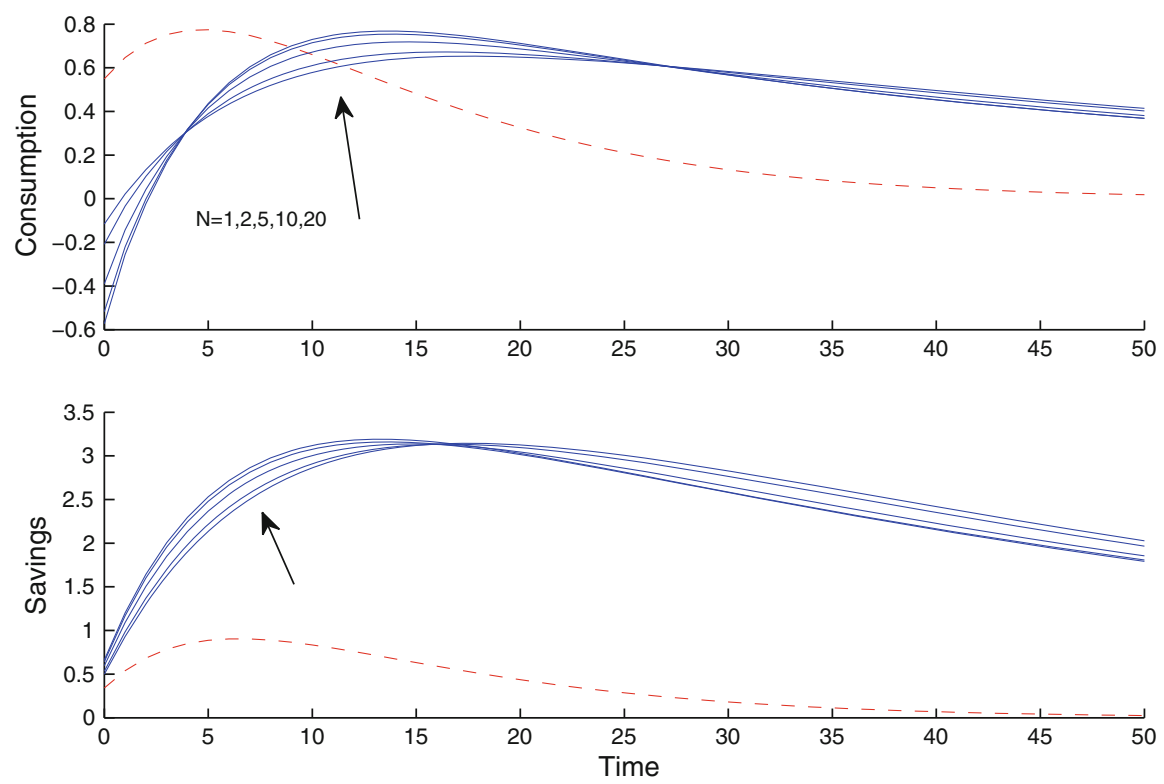

Fig. 1 Individual Behavior, Various Horizons. Impulse responses to a $1 \%$ technology shock, with $\theta=1$ and a zero-mass of boundedly rational agents. The dashed lines are impulse responses for rational agents, and the solid lines correspond to the zero-mass boundedly rational agent. The arrow indicates the direction in which $N$ increases

agent. In the figure, the dashed line indicates the behavior of the rational agents, and the solid lines indicate the behavior of the boundedly rational agents at various planning horizons $N=1,2,5,10,20$. The arrow indicates the way in which the impulse responses morph as the planning horizon increases. The exogenously set beliefs are given by $\psi_{c}=0.2, \psi_{r}=0.8$, and $\psi_{s}=0.999$, which are approximately the values that would arise in a restricted perceptions equilibrium when $N=1$.

A number of interesting features are evident from Fig. 1. First, notice that in response to the productivity shock, rational agents increase both savings and consumption, whereas boundedly rational agents shift toward savings and reduce consumption. These divergent responses to technology shocks are due to the backward-looking nature of the boundedly rational agents: the productivity shock increases the expected interest rate which raises the relative price of current consumption. This puts downward pressure on current consumption for both types of agents. However, rational agents, by correctly forecasting that future consumption will rise, lift current period consumption to promote smoothing. Because of their backward-looking beliefs, boundedly rational agents fail to predict the rise in future consumption and their current consumption falls. Increasing the planning horizon exacerbates this result by magnifying the interest rate effect.

The fall in consumption of the boundedly rational agents is very short-lived. Because savings increases rapidly - indeed faster for boundedly rational agents than for rational agents - forecasts of future consumption rise quickly as well. The higher consumption forecasts promote rapidly increasing consumption for the boundedly rational agents: 
they too want to smooth consumption across periods. In fact, we see that both the savings and consumption paths of the boundedly rational agents peak higher than the rational agents, and remain higher for at least 20 periods. As before, these effects are magnified by increasing the planning horizon. This result gives credence to our intuition that the presence of heterogeneity may amplify the propagation mechanism inherent in these models.

That consumption is counter-cyclical is, of course, a counter factual result. This is a feature of real business cycle models with boundedly rational or heterogeneous beliefs and was first noted by Kurz et al. (2003) in response to a monetary shock. Kurz et al. show that a monetary shock increases inflation expectations and hence the interest rate. Since monetary shocks do not increase the resources available, consumption decreases on impact. As noted above, the boundedly rational agents in our model are backward-looking and so in response to a productivity shock they increase their interest rate expectations but do not account for the greater resources available for consumption. To address this issue, in the equilibrium analysis in the next section we adopt the same variable capacity utilization mechanism assumed by Kurz et al. (2005). Capacity utilization is a proxy for resource unemployment and, as a result, increases the output impulse from a productivity shock. We will see in the next section that incorporating variable capacity utilization will lead to consumption dynamics that match the dynamics in the data.

That household responses to technology shocks differ, qualitatively and quantitatively, depending on their expectations has novel empirical implications. There is evidence of heterogeneity in consumption behavior (see Carroll 2000), but as far as we know the link with forecasting heterogeneity has not been empirically established. Exploration of this empirical implication is a topic for future research.

\subsection{Equilibrium behavior}

Now we turn to analyzing the model's restricted perceptions equilibria for various planning horizons and proportions of rational agents. We begin by allowing the planning horizon to vary, and by setting $\theta=0.22$. This section will demonstrate that business cycle propagation is increasing in $N$ and the fraction of boundedly rational agents $(1-\theta)$. In the next section, we calibrate $\theta, N$ to match the autocorrelation properties of output in the US at business cycle frequencies. Figure 2 plots the equilibrium output impulse responses to a unit shock to productivity.

Figure 2 illustrates that the presence of boundedly rational agents magnifies the model's propagation mechanism: a unit shock to productivity results in an output timepath that, under heterogeneous beliefs, has a higher peak and is more hump-shaped than it is under rational expectations; further, for long planning horizons output under heterogeneous beliefs remains higher for over 50 periods.

This presence of propagation magnification can be traced to the increased savings of the boundedly rational agents. Recall from Fig. 1 that, facing a unit productivity shock, boundedly rational agents save more than their rational counterparts, and maintain higher savings for some time. This increase in savings results in an increase in aggregate capital stock which increases firms' production levels. However, the 


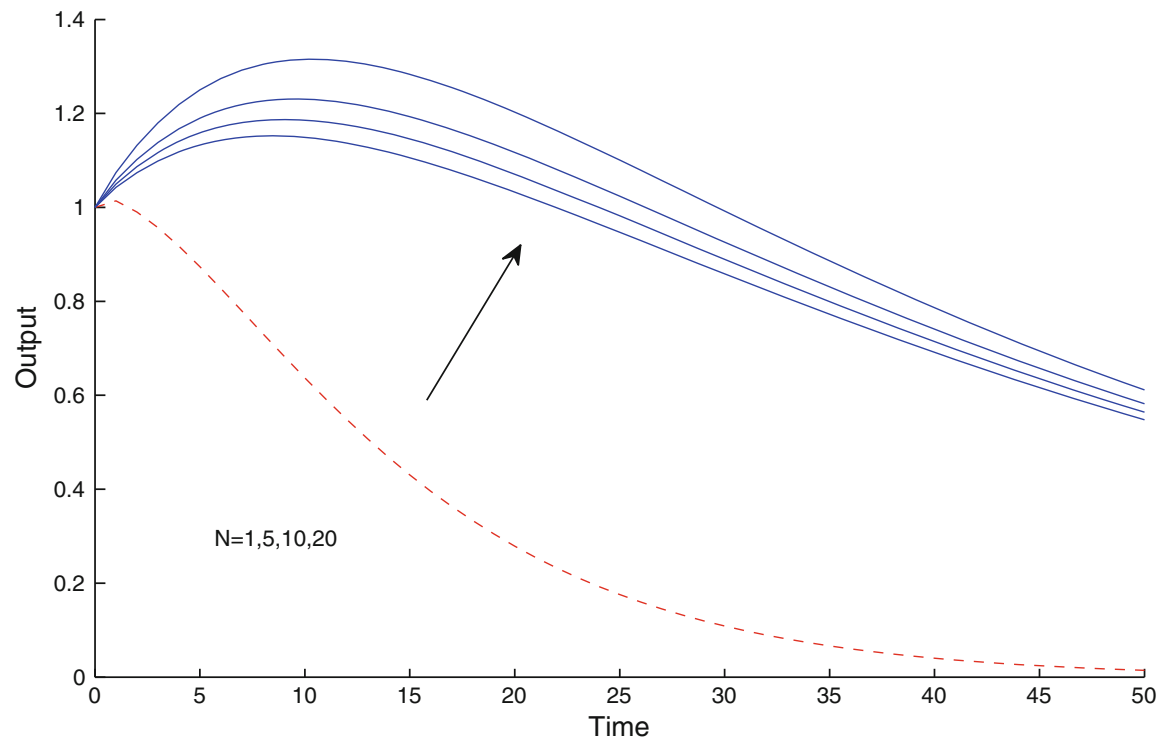

Fig. 2 Restricted perceptions equilibria, various horizons. Impulse response to a $1 \%$ technology shock. Dashed line is the RBC model, solid lines are the HBC model with various horizons $N$. The arrow indicates the direction of increasing $N$

increase in capital stock also lowers the marginal product of capital, and therefore the real interest rate, which encourages increased consumption. This increase mitigates somewhat the impact of the boundedly rational agents on equilibrium output, which is why the impulse response functions seen in Fig. 2 are less exaggerated than might be anticipated given the individual behavior witnessed in Fig. 1.

Varying the proportion of rational agents also leads to interesting comparative dynamics. Consider the impulse response functions presented in Fig. 3: here we take the planning horizon of boundedly rational agents to be $N=20$. The arrow indicates the way in which the impulse response functions morph as the proportion of rational agents increases.

A decrease in the proportion of rational agents magnifies the model's propagation mechanism: as $\theta$ becomes smaller, the model's dynamics are increasingly governed by the behavior of the boundedly rational agents, and their backward-looking forecasting models direct them to save more than rational agents.

\section{Quantitative results}

The previous section demonstrated that a heterogeneous expectations version of the neoclassical model, with inelastic labor supply, is capable of increasing the propagation of technology shocks. This section shows that a heterogeneous expectations version of the real business cycle model, extended to include variable capacity utilization, provides improved quantitative results over the benchmark RBC model. We again assume two types of agents, a fraction $\theta$ of which are rational, and now relax the 


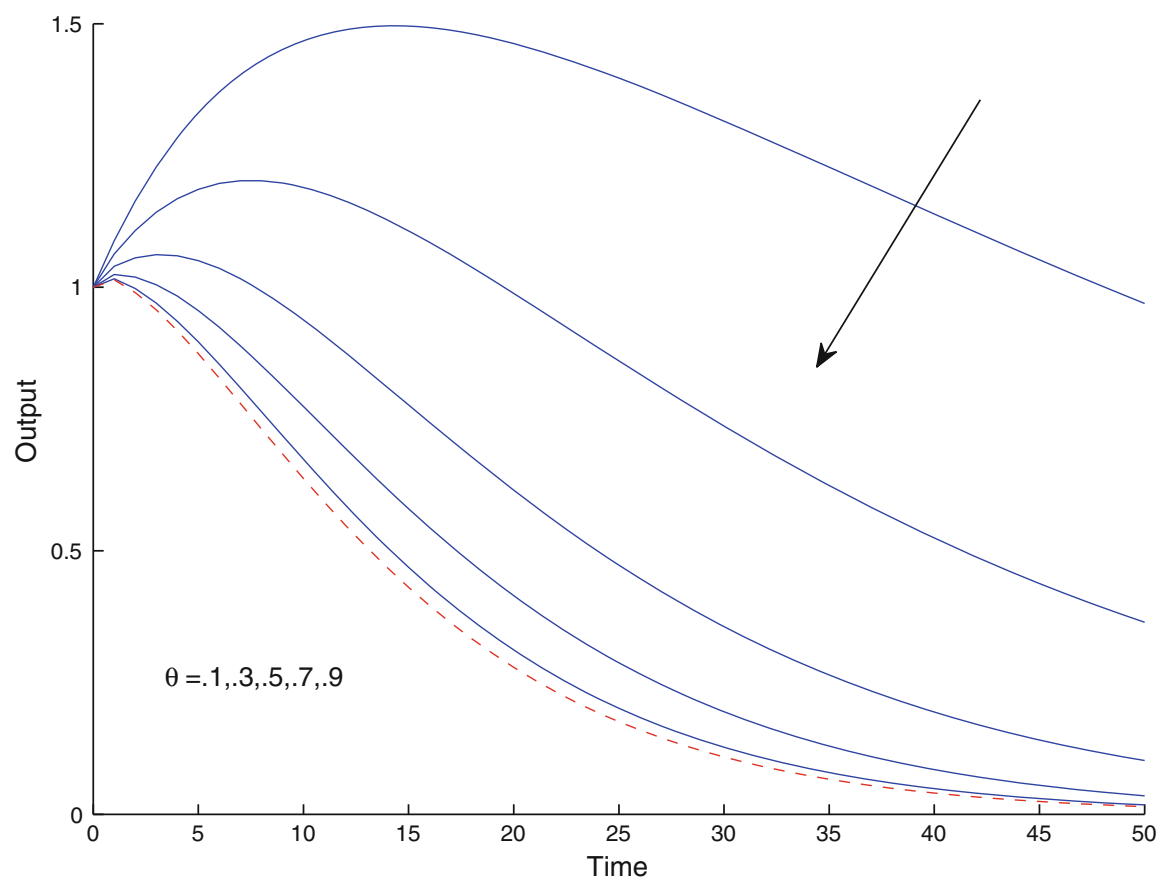

Fig. 3 Restricted perceptions equilibria, various proportions of rational agents, lagged timing. Impulse response to a $1 \%$ technology shock. Dashed line is the RBC model, solid lines are the HBC model with various fractions of rational agents $\theta$. The arrow indicates the direction of increasing $\theta$

inelastic labor supply assumption, i.e., $\Theta>0$. We calibrate the model with standard parameter configurations adopted by the RBC literature, and compare the fit of the HBC model to the RBC model for various second moments of interest.

There are a number of dimensions that the benchmark RBC model fails to match empirical business cycle properties. The previous section focused on the hump-shaped output impulse responses documented by Cogley and Nason (1995). The RBC models have also been criticized for relying on large technology shocks in order to match volatilities observed in data: see, for example, Summers (1986) and King and Rebelo (1999). A key feature of RBC models is the labor/leisure trade-off made in response to temporary movements in real wages. The standard model relies on an unrealistically high degree of labor elasticity to generate empirically realistic business cycles. Even with these assumptions, RBC models under predict volatility in output, consumption, and hours. Kurz et al. (2005) demonstrate that a heterogeneous expectations version of the RBC model can improve business cycle propagation and is capable of matching the empirical moments. We show that a heterogeneous expectations business cycle model, with a fraction of rational agents and a fraction of boundedly rational agents, can overcome the limitations of the RBC model and provide improved quantitative results.

We now calibrate the model in Sect. 2 according to the parameter values chosen by King and Rebelo (1999). These values facilitate model comparisons to US quarterly 
Table 1 Calibration

\begin{tabular}{lllllll}
\hline$\beta$ & $\alpha$ & $\delta$ & $\rho$ & $\eta$ & $\Theta$ & $\sigma_{v}$ \\
\hline 0.984 & $1 / 3$ & 0.025 & 0.979 & 1 & 3.48 & 0.0072 \\
\hline
\end{tabular}

data. Table 1 details the assumed parameter values. The baseline case corresponds to the basic model in King-Rebelo, with a large value for $\xi$ corresponding to the case where the rate of capacity utilization does not respond to changes in the marginal product of capacity utilization. We then follow Kurz et al. (2005) and Jaimovich and Rebelo (2009) and allow for variable capacity utilization. There is little empirical guidance for calibrating $\xi$, so for a benchmark we choose a value of 0.5 and then present results on the robustness of our findings when we select higher values and, in particular, the value $\xi=0.15$ selected by Jaimovich and Rebelo (2009).

Given the set of structural parameter values in Table 1 and values for $\theta, N$, a restricted perceptions equilibrium is pinned down. The results of the previous section demonstrate that increasing values of $N,(1-\theta)$ increase the output propagation of the equilibrium business cycle model. We calibrate $\theta, N$ in order to provide the best fit to a feature of US output other than the unconditional volatility and co movements that are the focus of the quantitative analysis below: we set $\theta, N$ in order to minimize the distance between the model implied autocorrelation function for output and the autocorrelation function for US (detrended) output. The calibrated values of $\theta, N$ will depend on the particular calibration of the structural parameters, and in particular, the capacity utilization elasticity parameter $\xi$.

We begin by computing business cycle moments for the HBC model with these standard parameter values. We subsequently show that for less elastic labor supply and smaller shocks, the HBC continues to fit the data well. The values $\eta=1$ and $\Theta=3.48$ imply that the Frisch labor supply elasticity is approximately 4, a value that is criticized as unrealistically high. We will also consider alternative values for $\eta, \Theta$ so that the labor supply elasticity is equal to one. The parameters governing the stochastic process for productivity are standard and are derived from the Solow residual. The size of the shocks have been criticized by Summers (1986) and Kurz et al. (2005). We follow Kurz et al. (2005) in also considering the properties of the model with much smaller shocks by setting $\sigma_{v}$ to a smaller value.

This section compares the fit of the RBC model, the HBC model, and quarterly US data from 1947.1-2009.2. To generate moments from the models, we simulate the (log-linearized) model for 248 periods and calculate key moments and correlations. We then repeat the simulation 20,000 times and average across simulations. ${ }^{8}$ To remain consistent with the RBC literature, we filter the data-actual and simulatedusing the Hodrick-Prescott filter. We report results on the unconditional volatilities of aggregate output, aggregate consumption, and aggregate hours. To illustrate the internal propagation of the model we calculate the contemporaneous correlations of

\footnotetext{
8 We found identical quantitative results when we simulated for 5000 periods and averaged across 5,000 simulations.
} 
Table 2 Business cycle moments: benchmark model with no capacity utilization
Calibrated values $\theta=0.1, N=20$

\begin{tabular}{llll}
\hline & Data & RBC & HBC \\
\hline$\sigma_{y}$ & 1.699 & 1.39 & 2.1 \\
$\sigma_{c}$ & 1.272 & 0.62 & 0.70 \\
$\sigma_{h}$ & 1.909 & 0.68 & 1.79 \\
$\operatorname{corr}(\mathrm{y}, \mathrm{h})$ & 0.86 & 0.97 & 0.95 \\
$\operatorname{corr}(\mathrm{y}, \mathrm{c})$ & 0.66 & 0.94 & 0.02 \\
$\operatorname{corr}(\mathrm{y}, \mathrm{z})$ & 0.78 & 1.00 & 0.99 \\
$\operatorname{corr}(\mathrm{c}, \mathrm{h})$ & 0.73 & 0.835 & -0.29 \\
\hline
\end{tabular}

output with consumption, hours and productivity shocks, and calculate the autocorrelation function. Table 2 presents the results for the baseline model without capacity utilization.

The first column of Table 2 presents moments for US quarterly data. ${ }^{9}$ The second column presents results for the RBC model, which arises by setting $\theta=1$, that are quantitatively identical to King and Plosser. These results illustrate a number of the common shortcomings of the benchmark RBC model. Output volatility, consumption volatility, and hours volatility in the model are lower than in the data. Moreover, the contemporaneous correlation between output and consumption, hours or productivity is close to one, while these correlations are much lower in data. Studies based on structural VAR identification of shocks place the fraction of output explained by technology shocks even lower. These results lead many to conclude that the RBC model has weak internal propagation.

The RBC literature has proposed a number of alternative formulations, particularly in the labor market, to address some of the shortcomings of the benchmark RBC model. This paper, following Kurz et al. (2003, 2005), proposes expectations heterogeneity as a mechanism to enhance the propagation of shocks. Column 3 of Table 2 illustrates the results for the $\mathrm{HBC}$ model under the standard calibration and without variable capacity utilization. These results assume that $\theta=0.10, N=20$, the calibrated values for the standard parameterization. Column 3 demonstrates that the HBC model increases the internal propagation of the RBC model. There is substantially more volatility in hours, with $163 \%$ more volatility than in the RBC model, which translates into $51 \%$ more output volatility and $13 \%$ more consumption volatility, than the representative agent model. The additional propagation provided by beliefs is seen in the lower correlation between output and hours.

The results in Table 2 also highlight a significant shortcoming in the standard equilibrium model with heterogeneous expectations. Consumption is essentially uncorrelated with output, while procyclical in the data, and, contrary to the data, negatively correlated with hours. This finding was anticipated by Kurz et al. and was seen in the impulse responses in the optimal growth model presented in the last section.

\footnotetext{
9 These data come from the St. Louis Federal Reserve Bank's FRED database. Output is measured as detrended log real GDP, consumption is log real personal consumption expenditures, and hours are in the nonfarm business sector.
} 
Table 3 Business cycle moments: benchmark model with capacity utilization
Calibrated values $\theta=0.35, N=25$

\begin{tabular}{llll}
\hline & Data & RBC & HBC \\
\hline$\sigma_{y}$ & 1.699 & 1.61 & 2.59 \\
$\sigma_{c}$ & 1.272 & 0.78 & 0.66 \\
$\sigma_{h}$ & 1.909 & 0.48 & 1.65 \\
$\operatorname{corr}(\mathrm{y}, \mathrm{h})$ & 0.86 & 0.99 & 0.97 \\
$\operatorname{corr}(\mathrm{y}, \mathrm{c})$ & 0.66 & 0.98 & 0.53 \\
$\operatorname{corr}(\mathrm{y}, \mathrm{z})$ & 0.78 & 0.99 & 0.99 \\
$\operatorname{corr}(\mathrm{c}, \mathrm{h})$ & 0.73 & 0.97 & 0.33 \\
\hline
\end{tabular}

The long-horizon expectations of boundedly rational agents place greater emphasis on their (backwards-looking) forecasts of interest rates. In response to a productivity shock they respond too strongly to interest rate innovations and do not properly account for the wealth effect when deciding on their consumption plan. Kurz et al. $(2003,2005)$ found similar counter factual negative consumption impulse responses to monetary shocks, which do not have the wealth effect that technology shocks do. To address this shortcoming they introduce variable capacity utilization as a proxy for the unemployment of resources. Because positive productivity shocks will increase the marginal product of capital, firms will increase their capital utilization and make more resources available. This increased propagation of shocks, real shocks in this paper, and monetary shocks in Kurz et al. can improve the empirical fit of the business cycle model when combined with heterogeneous expectations. This intuition is confirmed in Table 3.

The third column of Table 3 shows the results for the business cycle model with heterogeneous expectations with variable capacity utilization $(\xi=0.5)$, and calibrated values $\theta=0.35, N=25$. There are a number of features evident from the table. First, variable capacity utilization enhances the propagation of technology shocks. Second, consumption is now pro-cyclical and empirically close to the value observed in the data. Third, consumption and hours are now positively correlated, as they are in the data. Therefore, the combination of variable capacity utilization and heterogeneous expectations can improve the fit of the model to the data. The second column presents the corresponding results for the RBC version. This column demonstrates that capacity utilization enhances output propagation even under rational expectations, but at the expense of not enough volatility in hours. King-Rebelo must combine variable capacity utilization with indivisible labor in order to increase the model implied volatility of output and hours. Our results show that including variable capacity utilization and a fraction of boundedly rational agents into the equilibrium business cycle model can improve the fit.

If the model were extended to include monetary shocks, the counter-cyclical problem for consumption will be even more severe since monetary shocks do not increase aggregate resources available for consumption. We anticipate, though, that for an appropriate choice of the resource utilization elasticity $\xi$, similar results as Table 3 will arise. 


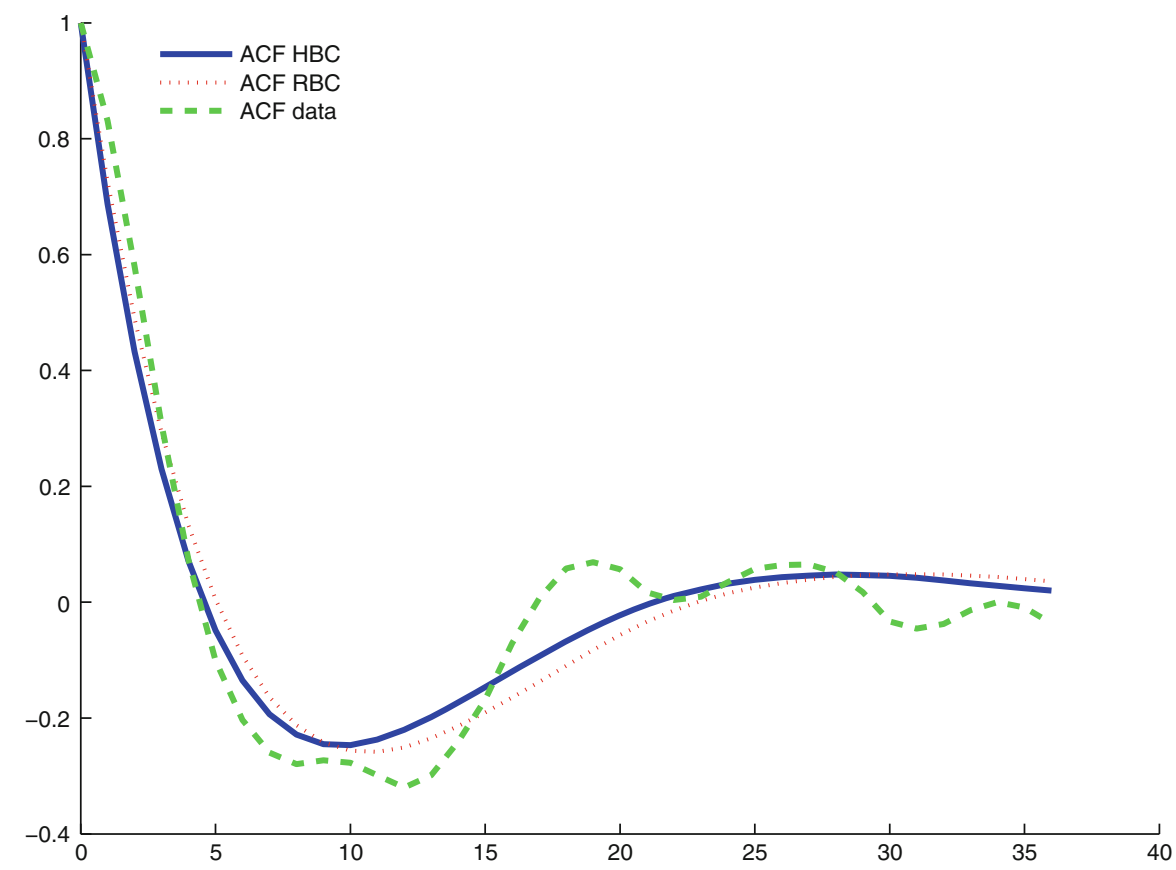

Fig. 4 Autocorrelation functions for data, RBC, and $\mathrm{HBC}$

The improved fit of the HBC model over the RBC model is not at the expense of its autocorrelation properties. Figure 4 plots the autocorrelation functions for detrended output in the data, the RBC model, and the HBC model. These autocorrelation functions were computed from the same data generating columns 2 and 3 of Table 3. This figure shows that the RBC model and HBC model do a good job capturing the positive autocorrelation at short lags, and the negative autocorrelation at mediumrange lags. Because the $\mathrm{HBC}$ model has very similar autocorrelation properties but substantially improved second moments, Table 3 and Fig. 4 demonstrate that the HBC model delivers a significantly better fit than the RBC model.

The empirical fit of the HBC model in column 3 of Table 3 adopts the standard $\mathrm{RBC}$ calibration for the technology shock process and, in particular, relies on large productivity shocks. Table 4 details the robustness of our results to alternative parameter values. Columns 2 and 3 of Table 4 demonstrate that the HBC model with smaller productivity shocks can improve the fit over the benchmark RBC model, e.g., column 2 of Table 3. The HBC results in columns 2-3 assume a much smaller value of $\sigma_{v}=0.003$, following the value set by Kurz et al. (2005). Column 2 is for the baseline variable capacity utilization case $\xi=0.5$, and column 3 is for the alternative $\xi=0.15$ employed by Jaimovich and Rebelo (J-R). Recall that lower values of $\xi$ increase the propagation of technology shocks. For each case the calibrated values are $\theta=0.1, N=25$.

The results in columns 2-3 show a substantial improvement, especially with the smaller $\xi=0.15$. The HBC model delivers output volatility that matches the data, and 
Table 4 Business cycle moments: robustness. For each specification, $\theta, N$ chosen to minimize the distance between the model implied autocorrelation function and the ACF for US output

\begin{tabular}{llllll}
\hline & Data & Small shocks & Small shocks J-R & J-R & Low elasticity \\
\hline$\sigma_{y}$ & 1.699 & 1.56 & 1.88 & 3.49 & 2.38 \\
$\sigma_{c}$ & 1.272 & 0.36 & 0.36 & 0.75 & 0.66 \\
$\sigma_{h}$ & 1.909 & 1.15 & 1.31 & 2.36 & 1.8 \\
$\operatorname{corr}(\mathrm{y}, \mathrm{h})$ & 0.86 & 0.97 & 0.99 & 0.98 & 0.96 \\
$\operatorname{corr}(\mathrm{y}, \mathrm{c})$ & 0.66 & 0.15 & 0.27 & 0.36 & 0.49 \\
$\operatorname{corr}(\mathrm{y}, \mathrm{z})$ & 0.78 & 0.98 & 0.98 & 0.97 & 0.99 \\
$\operatorname{corr}(\mathrm{c}, \mathrm{h})$ & 0.73 & -0.05 & 0.14 & 0.20 & 0.24 \\
\hline
\end{tabular}

The preferred specification sets $\theta=0.35, N=5, \xi=1$. The Jaimovich-Rebelo (J-R) sets $\xi=0.15, \theta=$ $0.15, N=25$. The small shocks $(\xi=0.5)$, small shocks J-R $(\xi=0.15)$ set $\sigma_{v}=0.0036, \theta=.1, N=25$. The lower elasticity sets $\theta=0.35, n=20, \xi=2$

has volatility in hours and consumption that are substantially closer to the data than in the benchmark RBC model. The smaller shocks, greater proportion of boundedly rational agents, and longer planning horizon, lead to a weaker connection between output and technology shocks. The key intuition for the improved fit of the HBC model relative to the benchmark $\mathrm{RBC}$ model is the increased propagation provided by the boundedly rational agents. A positive technology shock that increases the real wage and the real interest rate will induce substantial increased savings and hours by the boundedly rational agents. They forecast higher future real interest rates, leading them to increase labor and increase their savings accumulation. The longer the forecast horizon the stronger this response.

The remaining columns of Table 4 demonstrate the robustness of our results to alternative values for the elasticity parameter $\xi$ and the Frisch elasticity of labor supply. Column 4 demonstrates that by adopting the calibration in Jaimovich and Rebelo (2009) the propagation of the HBC model is enhanced even further, illustrating that a combination of bounded rationality and variable capacity utilization can deliver extremely large propagation effects. Column 5 demonstrates that this intuition continues to hold even for lower labor supply elasticities. The HBC results in column 5 occur when $\eta, \theta$ are set so that the Frisch elasticity equals one, $\sigma_{v}=0.0072$, and $N=20$. As in the previous formulations, the HBC model with a more reasonable labor supply elasticity is capable of improving the fit of business cycle models to data.

\section{Discussion of related research}

This paper demonstrates that heterogeneity in expectations can improve the internal propagation of equilibrium business cycle models. The literature has proposed several alternative paths. One promising avenue has been to incorporate "news" shocks into RBC models. For example, Beaudry and Portier (2006) illustrate that when households build news about future technology shocks into their current plans, then an equilibrium business cycle model is capable of generating empirically realistic business cycle fluc- 
tuations. A second approach has been to constrain household behavior. Deaton (1991) assumes some households face liquidity constraints. In Krusell and Smith (1996) households pay a utility cost to calculating the fully optimal consumption plan, or for no cost they can solve for an optimal linear consumption plan. Interestingly, there can exist an equilibrium with households split between being fully rational and constrained rational.

An approach more closely related to the present study has been to assume that agents have limited information and adopt econometric models to forecast future prices. Williams (2004) develops a standard RBC model where agents know the form of the (linear) law of motion under rational expectations, but they must learn in real time the model's parameters. Williams finds that adaptive learning does not enhance the internal propagation of the RBC model. Closely related, Huang et al. (2009), in a model similar to Williams (2004), demonstrate that with a one period planning/forecasting horizon and an optimally misspecified model, the inter-temporal substitution effects can be strengthened and improve the propagation of RBC models. Importantly, these two papers assume households form forecasts based on "Euler equation learning," e.g., Marcet and Sargent (1989b) and Bullard and Mitra (2002), which requires agents to only form forecasts one period ahead in order to satisfy their Euler equation. On the other hand, Eusepi and Preston (2008) consider a closely related model where agents, conditional on their current parameter estimates, satisfy their Euler equation and their lifetime budget constraint, requiring them to forecast infinitely far into the future. Eusepi and Preston demonstrate that, under "infinite horizon learning," the median impulse response across simulated economies exhibit hump-shaped responses to transitory technology shocks. We expect that the increased propagation channel identified in this paper would arise with the infinite horizon approach of Eusepi-Preston, although the behavioral assumptions differ.

As mentioned earlier, the work most closely related to this paper is Kurz et al. (2003, 2005). These two papers build on the Rational Belief Equilibrium of Kurz (1994). The Rational Belief approach begins with the premise that the economy is nonstationary and that agents have an infinite history of data with which they compute the stationary empirical measure for observed variables. In a rational belief equilibrium, economic agents hold diverse beliefs about future state variables and these beliefs are aligned with the stationary empirical measure. The idea is that diverse beliefs are compatible with the same empirical evidence and that it can be shown that, in order for beliefs to be aligned with the long-run averages of the empirical distribution, forecasting functions must be changing. The diversity and varying of beliefs has important implications for the economy. In Motolese (2001, 2003) and Kurz et al. (2003), it gives a critical role for monetary policy in stabilizing expectations and the economy. In Kurz et al. (2005), a rational belief equilibrium is able to replicate business cycle facts even with much smaller productivity shocks. The works by Kurz and Motolese (2010) and Guo et al. (2010) demonstrate strong empirical implications of rational beliefs for asset pricing and asset returns.

The approach to heterogeneity in this paper is motivated in part by the Rational Belief literature's emphasis on the interaction between heterogeneous agents (e.g. Kurz 2010), but is developed using the Euler equation technique emphasized in the learning literature. The results in this paper show that an equilibrium business cycle model with 
a fraction of rational agents and a fraction of boundedly rational agents, each behaving in an economically reasonable manner, can better explain business cycle facts than the corresponding rational expectations model. The approach to heterogeneity is also closely related to a number of other models with heterogeneous boundedly rational agents. For example, Branch and McGough (2009) demonstrate that the implications for monetary policy in a New Keynesian model with the same model of heterogeneity as in this paper are significantly different from rational expectations: adherence to a "Taylor Principle" for monetary policy that stabilizes the economy under rational expectations may destabilize under heterogeneous expectations. A similar result is found in Branch and Evans (2010) and De Grauwe (2010) where there is an endogenous distribution of agents across boundedly rational forecasting models.

The results in Wieland and Wolters (2010) provide further evidence in favor of heterogeneous models used by agents to form forecasts. Wieland and Wolters take six standard New Keynesian models, estimate them with real-time historical data, and then generate forecasts from the estimated models around the NBER-dated turning points. They compare the distribution of the model-based forecasts with the private forecasts in the Survey of Professional Forecasters. They find that the mean forecasts, and degrees of heterogeneity, in the model-based forecasts and the SPF are remarkably similar. These results provide strong evidence in favor of belief diversity among the private-sector as well as policymakers. The results in this paper, along with others in the rational belief equilibrium literature, demonstrate that belief diversity have powerful implications for business cycle dynamics and stabilization policy.

\section{Conclusion}

This paper incorporates heterogeneous expectations into an equilibrium business cycle model. We assume a competitive economy populated by two different types of households, each selecting plans for consumption/savings and labor supply. The first group of agents are fully rational and form their expectations rationally while the other group of agents employ a set of misspecified statistical models through which they form their expectations. With a statistical model in hand, the group of agents who are boundedly rational must decide on a household plan by satisfying a set of optimality conditions. A fraction of agents hold restricted perceptions because they lack the forecasting sophistication required by rational expectations. We require that households have the same sophistication in decision making as in forecasting, thereby avoiding a cognitive dissonance. The results of this paper demonstrate that a heterogeneous expectations business cycle model is capable of increasing the internal propagation of real business cycle models.

The approach of this paper is most closely related to Kurz et al. (2005), who develop a business cycle model with diverse beliefs, variable capacity utilization, and monetary and technology shocks. They show that their model can match key business cycle moments even with smaller shocks, e.g., $\sigma_{v}=0.003$. Their approach to heterogeneity is complementary to ours. They adopt the rational belief approach that requires agents' subjective beliefs to be consistent with the empirical distribution generated by those beliefs. Their beliefs, like ours, are optimally misspecified. The primary differ- 
ence between their study and ours, is that they study the interaction between diverse, possibly misspecified, beliefs, while the present paper studies the interaction between rational and boundedly rational beliefs.

The quantitative results presented in this paper suggest heterogeneous expectations and bounded rationality/optimality as a promising avenue for future research on business cycles. There is an extensive literature that considers alternative assumptions for labor markets, preferences, shocks, capacity utilization, and so on, that have been useful for improving the fit of RBC models. The results in this paper suggest that also including heterogeneous expectations into these models may also improve their fit and at the same time brings more realism to the model by departing from the representative agent structure.

Open Access This article is distributed under the terms of the Creative Commons Attribution Noncommercial License which permits any noncommercial use, distribution, and reproduction in any medium, provided the original author(s) and source are credited.

\section{References}

Beaudry, P., Portier, F.: When can changes in expectations cause business cycle fluctuations in neo-classical settings. J Econ Theory 135, 458-477 (2006)

Blanchard, O., Kahn, C.: The solution of linear difference models under rational expectations. Econometrica 48, 1305-1311 (1980)

Branch, W.A.: The theory of rationally heterogeneous expectations: evidence from survey data on inflation expectations. Econ J 114, 592-621 (2004)

Branch, W.A., Evans, G.W.: Intrinsic heterogeneity in expectation formation. J Econ Theory 127, 264295 (2006)

Branch, W.A., Evans, G.W.: Monetary policy and heterogeneous expectations. Econ Theory (this volume) (2010)

Branch, W.A., McGough, B.: Multiple equilibria in heterogeneous expectations models. Contrib Macroecon 4(1), 1-16 (2004)

Branch, W.A., McGough, B.: A new keynesian model with heterogeneous expectations. J Econ Dyn Control 33, 1036-1051 (2009)

Brock, W.A., Hommes, C.H.: A rational route to randomness. Econometrica 65, 1059-1095 (1997)

Bullard, J., Mitra, K.: Learning about monetary policy rules. J Monetary Econ 49, 1105-1129 (2002)

Carroll, C.D.: Requiem for the representative consumer? Aggregate implications of microeconomic consumption behavior. Am Econ Rev Papers Proc 90(2), 110-115 (2000)

Cogley, T., Nason, J.: Output dynamics in real business cycle models. Am Econ Rev 85, 492-511 (1995)

De Grauwe, P.: Animal spirits and monetary policy. Econ Theory (this volume) (2010)

Deaton, A.: Saving and liquidity constraints. Econometrica 59(5), 1221-1248 (1991)

Eusepi, S., Preston, B.: Expectations, learning and business cycle fluctuations. mimeo (2008)

Evans, G.W., Honkapohja, S.: Learning and Expectations in Macroeconomics. Princeton: Princeton University Press (2001)

Evans, G.W., Honkapohja, S.: Monetary policy, expectations and commitment. Scand J Econ 108, 1538 (2006)

Evans, G.W., McGough, B.: Learning to optimize. Working paper (2009)

Guo, W.C., Wang, F.Y., Wu, H.M.: Financial leverage and market volatility with rational beliefs. Econ Theory (this volume) (2010)

Huang, K., Liu, Z., Zha, T.: Learning, adaptive expectations and technology shocks. Econ J 119, 377405 (2009)

Jaimovich, N., Rebelo, S.T.: Can news about the future drive the business cycle? Am Econ Rev 99(4), 10971118 (2009)

King, R.G., Rebelo, S.T.: Resuscitating real business cycles. In: Taylor, J., Woodford, M. (eds.) Handbook of Macroeconomics, vol. 1. Amsterdam: Elsevier (1999) 
Krusell, P., Smith, A.A. Jr.: Rules of thumb in macroeconomic equilibrium: a quantitative analysis. J Econ Dyn Control 20(4), 527-558 (1996)

Kurz, M.: On the structure and diversity of rational beliefs. Econ Theory 4, 1-24 (1994)

Kurz, M.: The role of market belief in economic dynamics: an introduction. Econ Theory (this volume) (2010)

Kurz, M., Jin, H., Motolese, M.: Endogenous fluctuations and the role of monetary policy. In: Knowledge, Information and Expectations in Modern Macroeconomics: Essays In Honor of Edmund S. Phelps, Chap. 10, pp. 188-227 (2003)

Kurz, M., Jin, H., Motolese, M.: The role of expectations in economic fluctuations and the efficacy of monetary policy. J Econ Dyn Control 29, 2017-2065 (2005)

Kurz, M., Motolese, M.: Diverse beliefs and time variability of risk premia. Econ Theory (this volume) (2010)

Marcet, A., Sargent, T.J.: Convergence of least-squares learning in environments with hidden state variables and private information. J Political Econ 97, 1306-1322 (1989a)

Marcet, A., Sargent, T.J.: Convergence of least-squares learning mechanisms in self-referential linear stochastic models. J Econ Theory 48, 337-368 (1989b)

Mavroeidis, S., Chevillon, G., Massmann, M.: Inference in models with adaptive learning. J Monetary Econ 57, 341-351 (2009)

Milani, F.: Expectations, learning and macroeconomic persistence. J Monetary Econ 54, 2065-2082 (2007)

Motolese, M.: Money non-neutrality in a rational belief equilibrium with financial assets. Econ Theory 18, 97-116 (2001)

Motolese, M.: Endogenous uncertainty and the non-neutrality of money. Econ Theory 21, 317-345 (2003)

Preston, B.: Adaptive learning, forecast-based instrument rules and monetary policy. J Monetary Econ 53, 507-535 (2006)

Sargent, T.J.: Bounded Rationality in Macroeconomics. Oxford: Oxford University Press (1993)

Sargent, T.J.: The Conquest of American Inflation. Princeton: Princeton University Press (1999)

Sargent, T.J.: Evolution and intelligent design. Am Econ Rev 98, 5-37 (2008)

Summers, L.H.: Some skeptical observations on real business cycle theory. Fed Reserv Bank Minneap Q Rev 10, 23-27 (1986)

Taylor, J., Woodford, M. (Eds.) Handbook of Macroeconomics, Vol. 1. Amsterdam: Elsevier (1999)

Wieland, V., Wolters, M.: The diversity of forecasts from macroeconomic models of the US economy. Econ Theory (this volume) (2010)

Williams, N.: Adaptive learning and business cycles. working paper (2004) 